\title{
The Effects of Education and Telephone Nurse Follow-Up (Tele-Nursing) on Diabestes Management Self-Efficacy in Patients with Type 2 Diabetic Referred to Hamadans Diabetes Center in 2018
}

\author{
Morteza Shamsizadeh", Soheila Shaadi², Younes Mohammadi ${ }^{3}$, Seyed Reza Borzou *4
}

1. Instructor, Department of Medical Surgical Nursing, School of Nursing and Midwifery, Hamadan University of Medical Sciences, Hamadan, Iran

2. Student Research Committee, Hamadan University of Medical Sciences, Hamadan, Iran

3. Associate Professor, Non-Communicable Disease Modeling Research Center, Department of Epidemiology, School of Health, Hamadan University of Medical Sciences, Hamadan, Iran

4. Associate Professor, Department of Medical Surgical Nursing, School of Nursing and Midwifery, Hamadan University of Medical Sciences, Hamadan, Iran

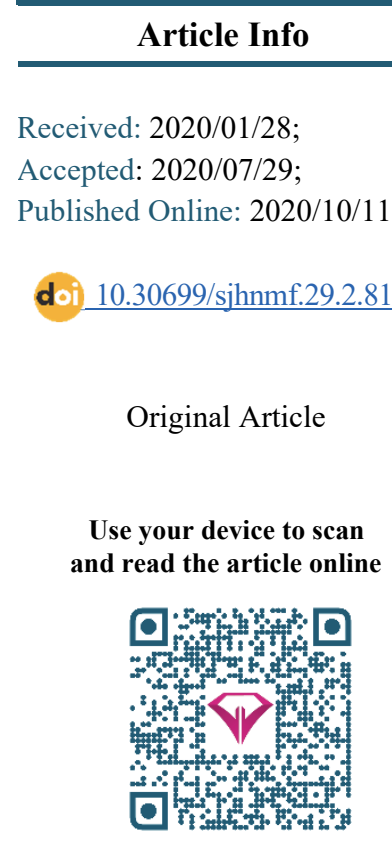

\begin{abstract}
Introduction: Diabetes is a common and costly disease. Nursing care services, not only are effective in reducing costs but also improve the quality of life and the relationship between the patient and the nurse. The aim of this research was evalution of telephone nursing Follow-up effects on self-efficacy in women with type 2 diabetes mellitus in Hamadan.
\end{abstract}

Methods: In this Clinical Trial study, 58 type 2 diabetic patients who met the inclusion criteria were recruited in Hamadan diabetes center by simple sampling. Patients were divided into two groups using block randomization. Data were collected using demographic and disease information questionnaire and Diabetes Management Self-Efficacy Scale (DMSES). Intervention in the experimental group was done by telephone nursing for 12 weeks in which phone calls were made during the first month (twice a week) and the second month (once a week). Phone nursing content included emphasis on diabetic diet, timely medication use, insulin injection, recreation and exercise, self care, stress management techniques, communication skills training, and more. The average duration of the call was 10-15 minutes on each call, and the time of phone call was agreed between 8 a.m. and 6 p.m. Patients were told that telephone nursing is free so patients could contact the researcher by phone or text if they had any questions. It should be noted that the patients in the control group received only the follow-up and routine care of the Hamadan diabetes center. Finally, the data were analyzed using IBM SPSS Statistics version 19 software.

Results: Findings of the study showed that the mean of self-efficacy in both groups before intervention was not statistically significant $(P=0.15)$. After training the intervention group, the mean self-efficacy at one and two months after treatment was significantly improved compared to the control group $(P<0.001)$.

Conclusion: According to the findings of this study, it can be concluded that nurse telephone follow-up was effective in promoting self-efficacy in patients with diabetes.

Keywords: Telephone nurse follow-up, Self-efficacy, Type 2 diabetes mellitus

Copyright (C) 2021, This is an original open-access article distributed under the terms of the Creative Commons Attribution-noncommercial 4.0 International License which permits copy and redistribution of the material just in noncommercial usages with proper citation.

How to Cite This Article:

Shamsizadeh M, Shaadi S, Mohammadi Y, Borzou S R. The Effects of Education and Telephone Nurse Follow-Up (Tele-Nursing) on Diabestes Management Self -Efficacy in Patients with Type 2 Diabetic Referred to Hamadans Diabetes Center in 2018. Avicenna J Nurs Midwifery Care. 2021; 29 (2):81-90 
بررسى تأثير آموزش و يِيحيرى تلفنى يرستار (تلهنرسينَ) بر خودكار آمدى در مديريت بيماران ديابتى نوع ץ: يك مطالعة كار آزمايى بالينى

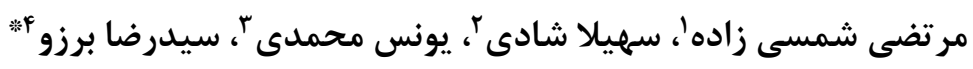

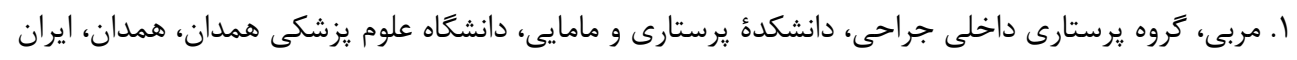

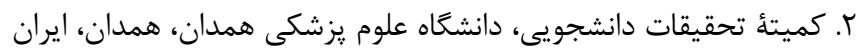

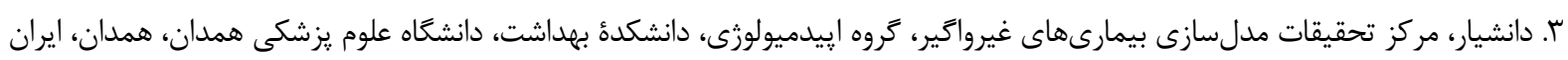

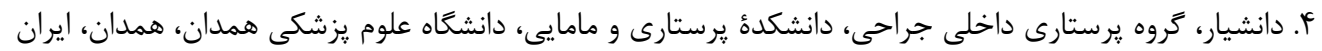

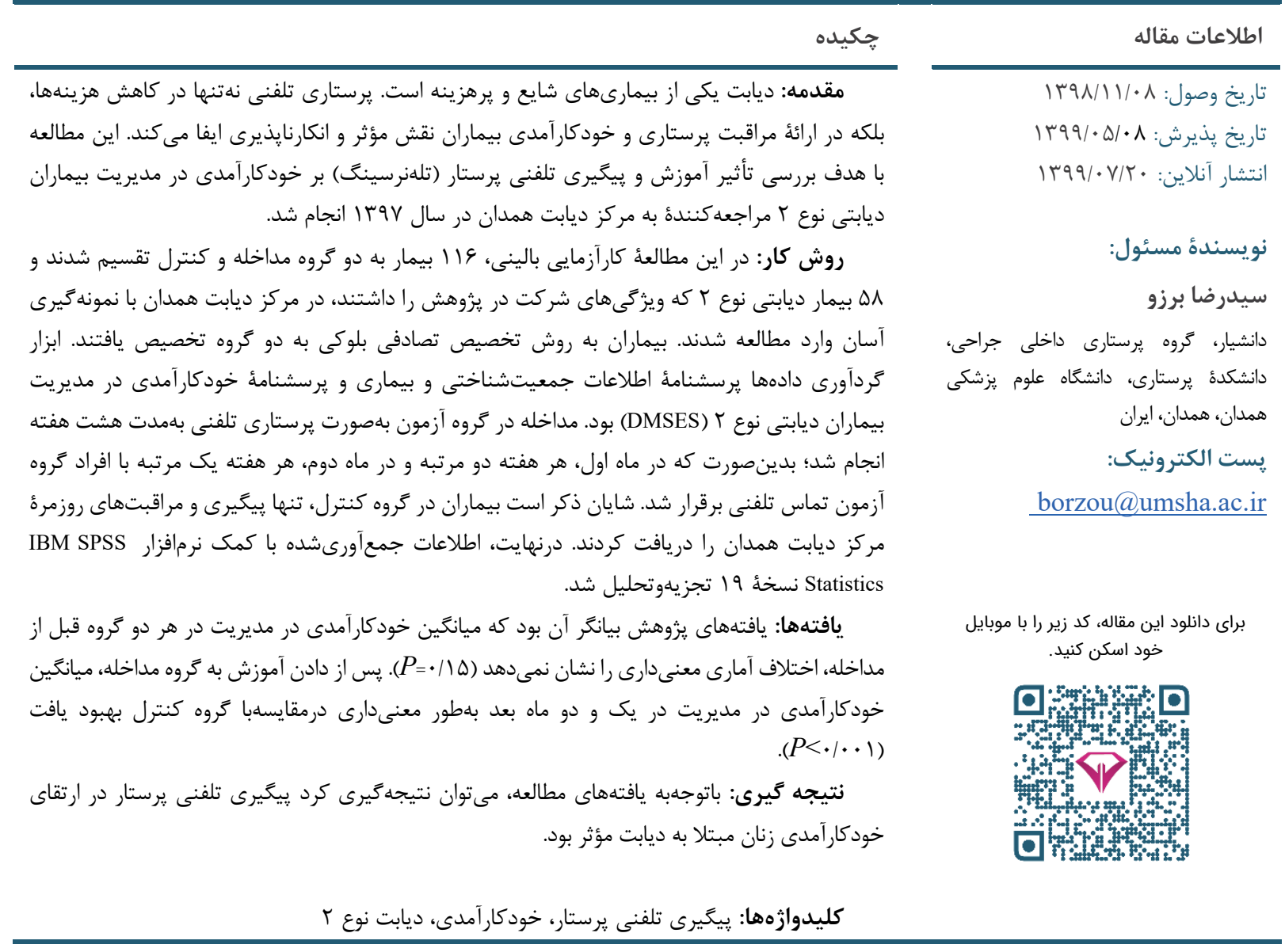

مقدمه

اجتماعى زيادى به سراسر دنيا تحميل كرده است [ب]. باتوجه

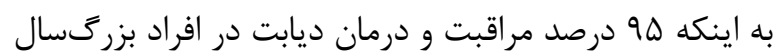

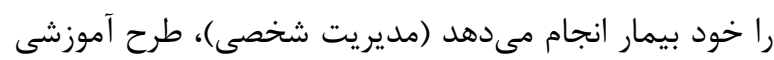
جامعى كه با نيازهاى يادگيرى مددجويان متناسب باشد، مى تواند هزينههاى مراقبتى را كاهش دهد.
ديابت نوعى بيمارى متابوليكى محسوب مىشود كه تظاهر

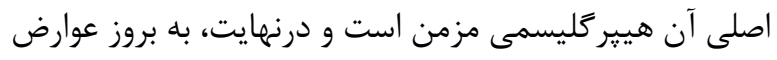

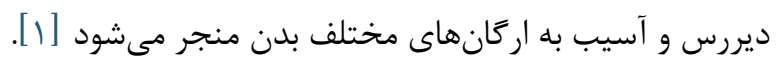

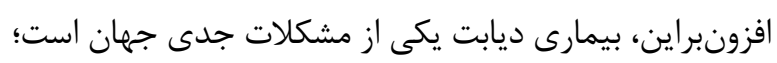

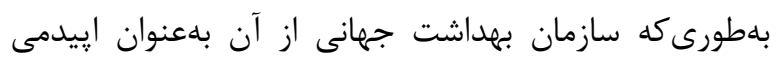

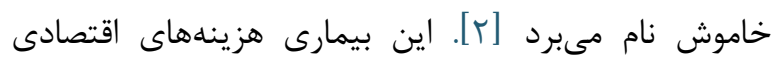




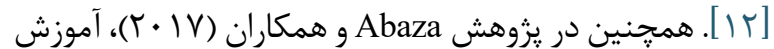
ازطريق ييام متنى موجب ارتقاى خودكارآمدى در مديريت

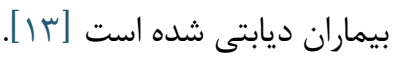

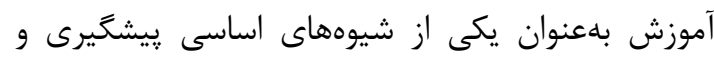
درمان و كنترل بيمارىهاى مزمن، ازجمله ديابت است و همواره سهمم بيشترى در حفظ سلامت و بهبودى بيماران ايفا مى كند و

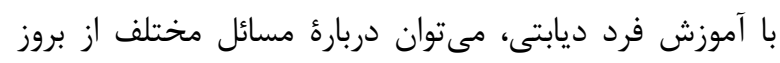
عوارض زودرس و ديررس اين بيمارى ييشگيرى كرد و زندى إنى

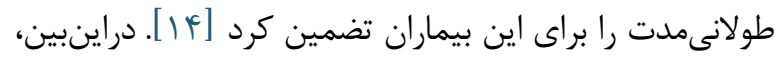

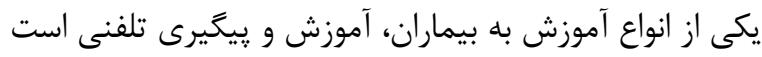
كه در تسهيل و بهبود مراقبت و ايجاد محيطى براى يادئ ياديرى تأثير بسزايى مى كذارد [ه ا 1 ].

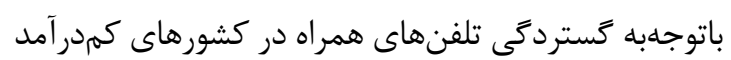

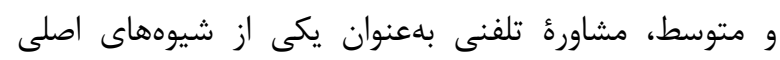
رِيشگيرى و درمان و كنترل مداوم است كه در آن، ازطريق تلفن با بيمار ارتباط دوستانهاى برقرار و اطلاعات مفيدى به او داد داده

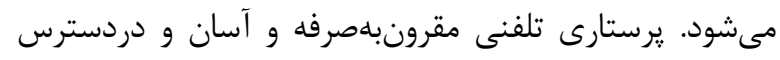

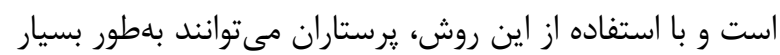

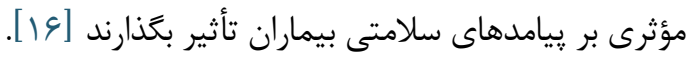

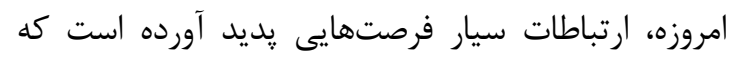

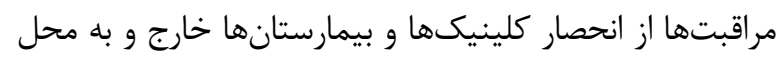

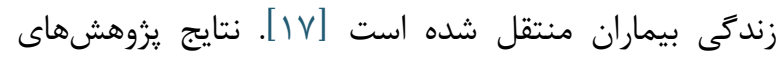

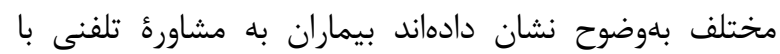

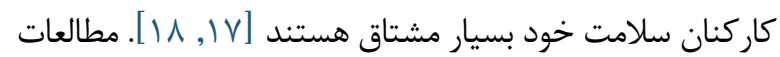
انجام كرفته در ساير كشورها سرويس تلفنى را روشى مؤثر براى קييخيرى وضعيت سلامتى بيماران با بيمارىهاى مزمن معرفى

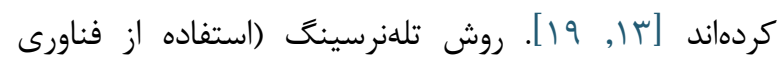
اطلاعات و ارتباط ازراهدور در يرستارى) با ارائٔ مراقبت با استفاده از وسايل ارتباطى، ازقبيل اينترنت و تلفن و فيلم ويدئويى مىتواند باعث تسهيل دسترسى به مراقبت مؤثر در منزل، كاهش هزينهها، بهبود روابط بين مددجو و يرستار، كاهش معاينات

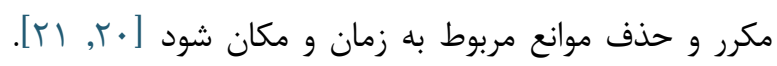

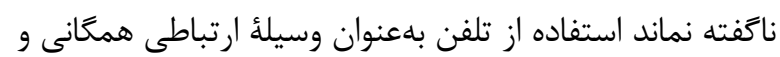

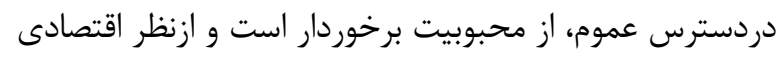

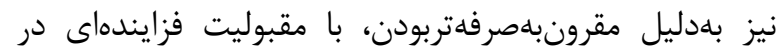

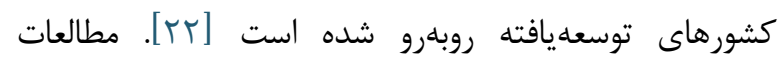

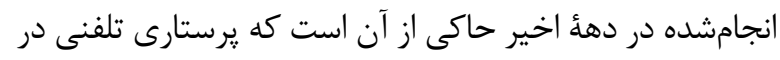

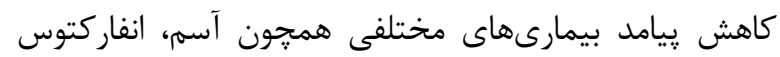

درحالحاضر، ديابت \& \&ץميليون نفر را در سراسر دنيا

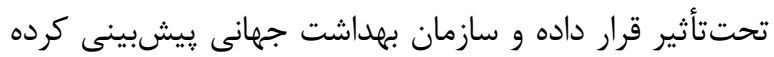

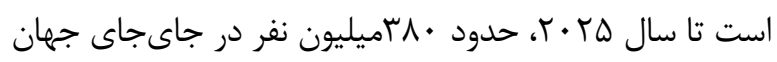

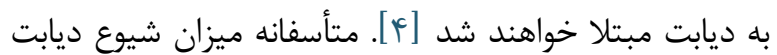
در جمعيت ايرانى نيز روبهافزايش است [ه]]. حدود نيمى از موارد

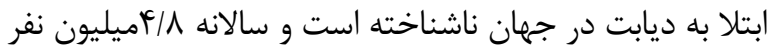

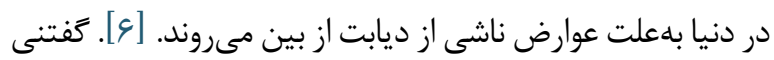

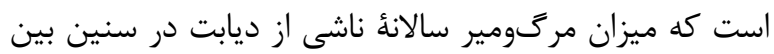

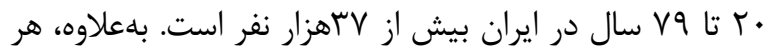

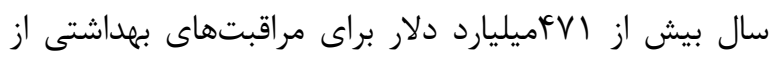
بيماران ديابتى صرف مىشود و ميانكين هزينهُ درمان هر فرد برد

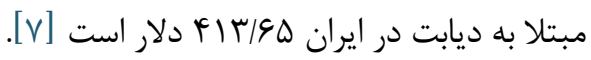
در مبتلايان به ديابت، عوارض بسيار جدى وجود دارد كه به دابه

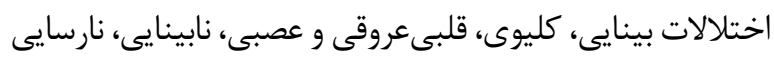
شديد كليه، سكته قلبى يا مغزى و قطع عضو منجر مى ديود. درصورتى كه اقدام مناسب براى يِيشگيرى و كنترل و درمان اين

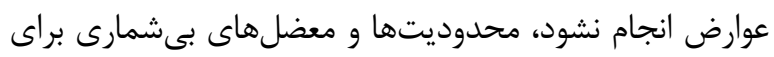

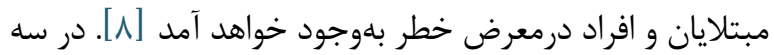
دهأ كذشته، با وجود يِيشرفتهاى درخورملاحظهاى كه در

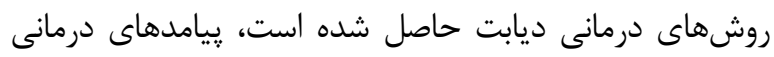
هنوز فاصلهُ بسيار زيادى با سطح مطلوب درمان دان در كشورهاى

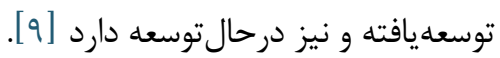

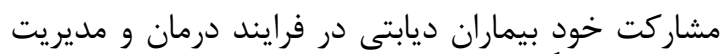

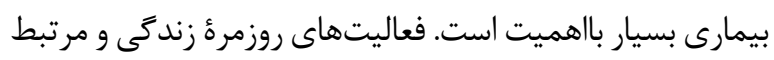
با بيمارى، مانند فعاليت بدنى، رفتارهاى تغذيهاى، بايش قندخون، تنظيم برنامههاى روزانهٔ مرتبط با سلامت و بيمارى و و

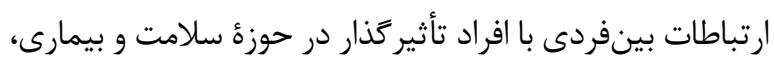

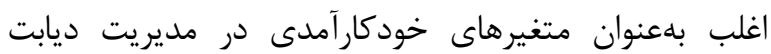

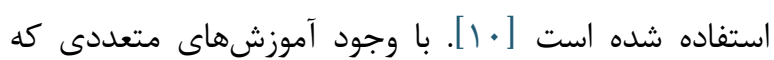

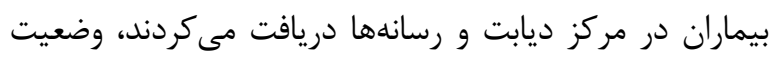

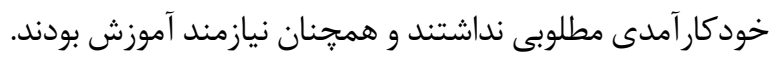
افزونبراين، بيماران در كنترل علائم و ييامدهاى مربوط به ندان بيمارى خود ضعف داشتند و بلهنوعى در مديريت بيمارى خود

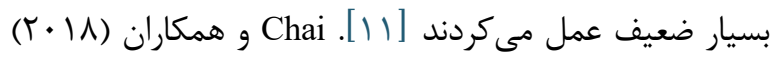
در مطالعه خود دريافتند كه مديريت بيماران بر علائم و بيمارى خود ضعيف است و بيمارانى كه مداخلئ آموزشى دريافت كرده بودند، علائم روحىروانى و قندخون بهترى درمقايسهبا گروه كنترل داشتند؛ بنابراين، آموزش به بيماران مؤثر بوده است بتري 
آزمون و هF نفر در كروه كنترل بررسى شدند. ابزار و روش

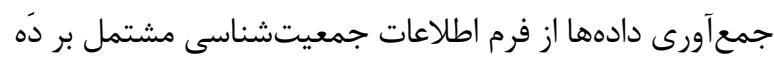
سؤال و مقياس خودكارآمدى در مديريت ديابت (DMSES)

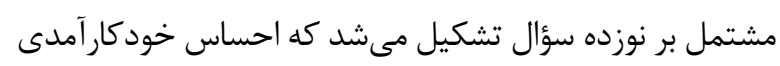
و توانايى بيماران ديابتى را در ابعاد مختلف آن، مانند رعايت

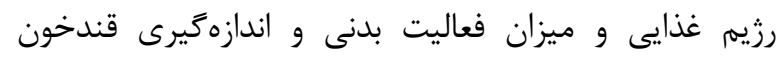

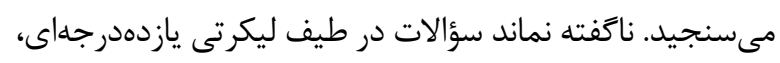

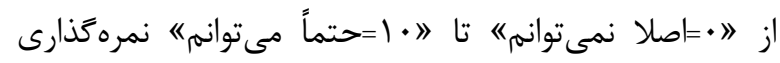

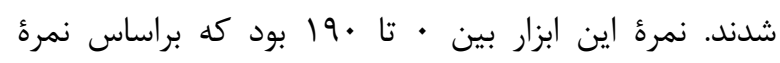

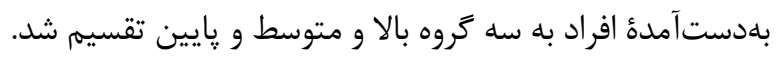

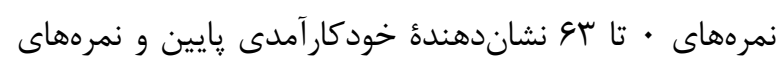

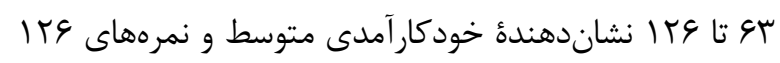

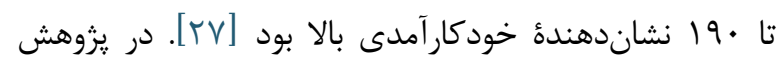
و همكاران (r. Van der Ven

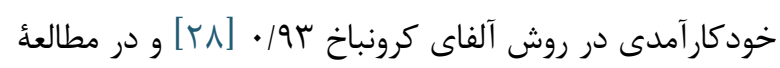

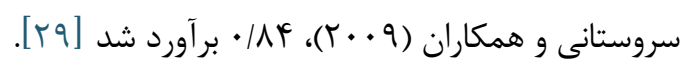

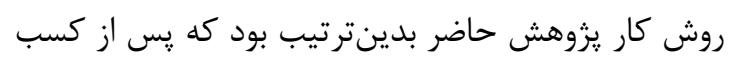

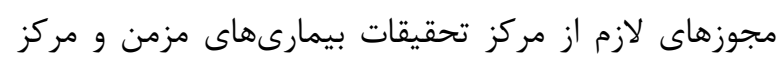

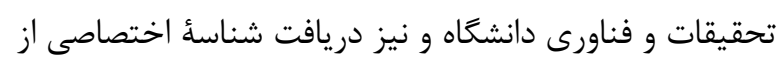
كميته اخلاق، بلهصورت مستمر در تمام ايام هفته بلهغير از داز

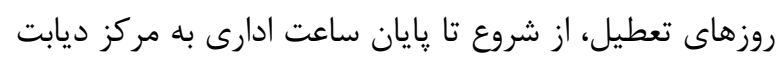

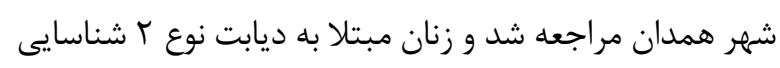

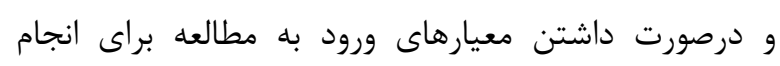

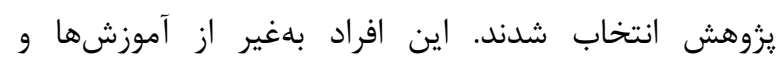

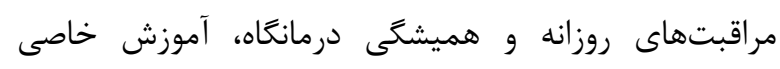

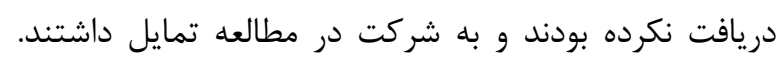

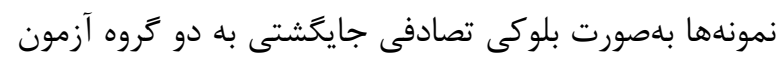

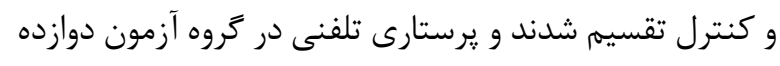

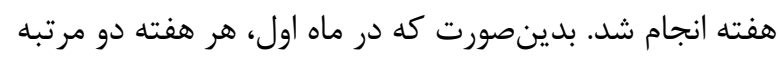

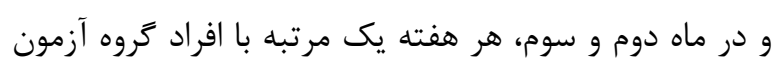

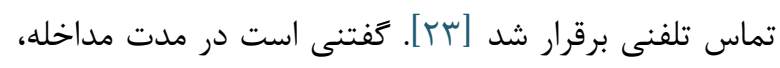

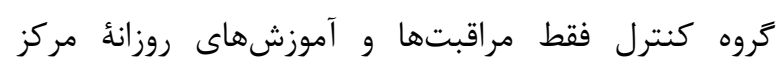

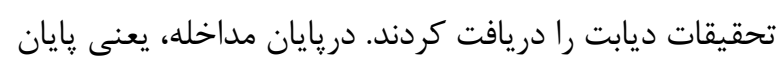

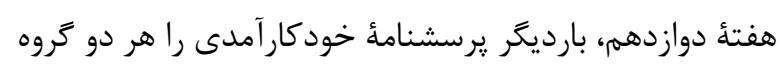
آزمون و كنترل تكميل كردند.

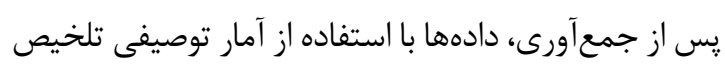

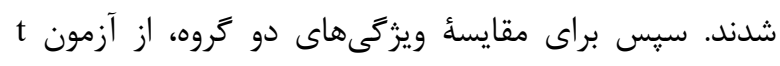

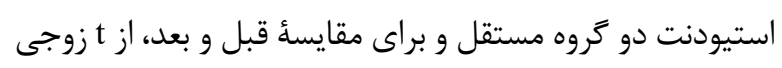

ميو كارد، سرطان و ديابت مؤثر است [ـr[ب]. يرستارى تلفنى در

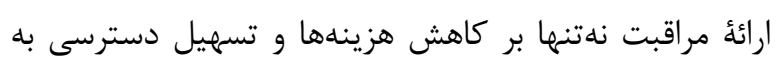

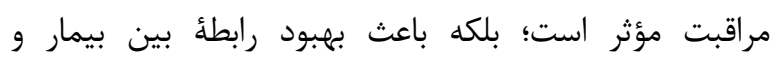

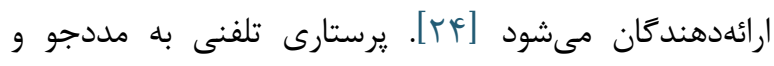

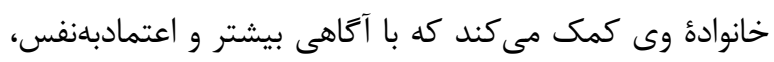

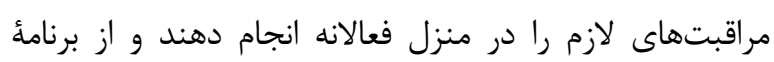

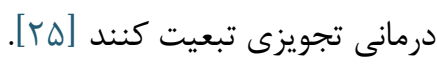

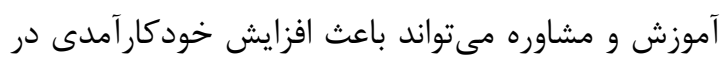

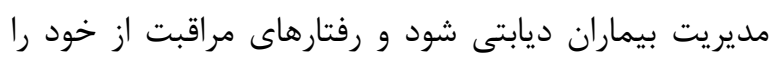

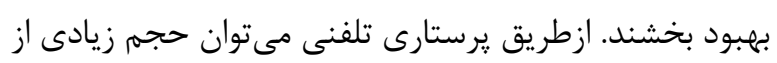

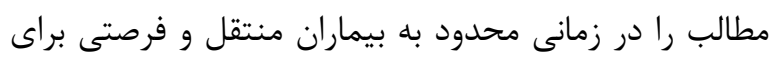

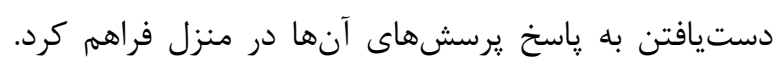

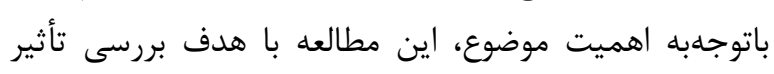

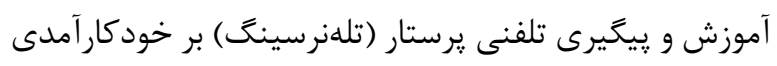

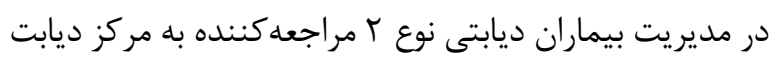

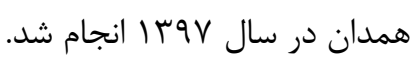

$$
\text { روش كار }
$$

اين يزوهش از نوع كارآزمايى بالينى بود كه روى زنان مبتلا

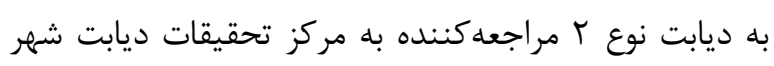

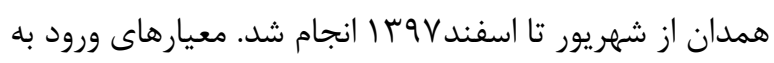

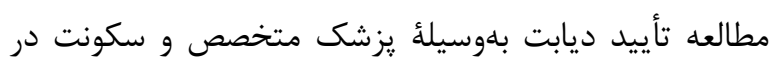

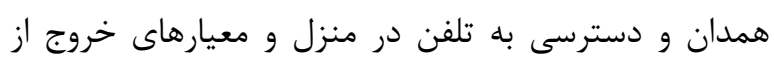

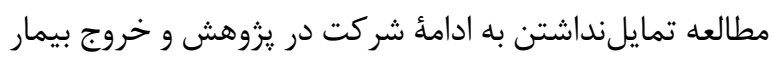

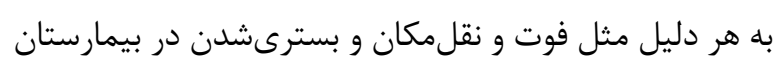

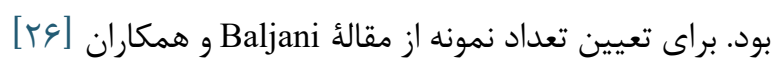

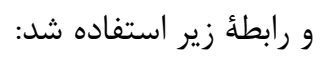

$$
n=\frac{\left(Z_{1-\frac{\alpha}{2}}+Z_{1-\beta}\right)^{2}\left(\sigma_{1}^{2}+\sigma_{2}^{2}\right)}{d^{2}}
$$

در اين رابطه،

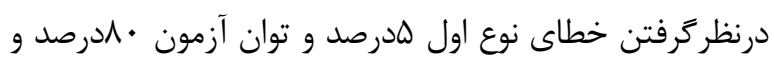

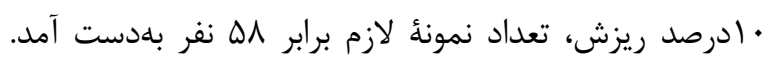

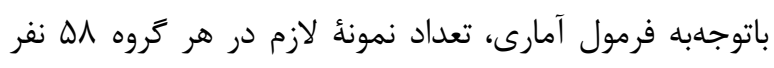

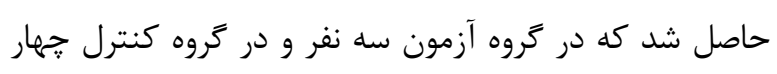

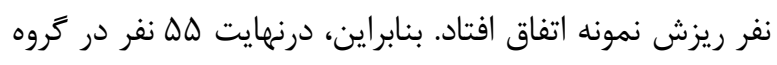


آزمون، بيشترين درصد زنان متأهل (I

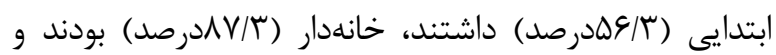

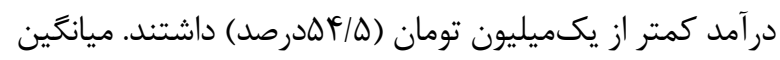

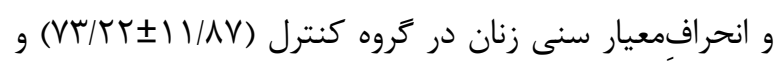

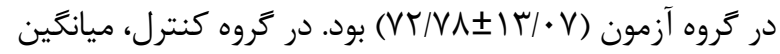

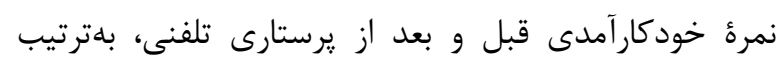

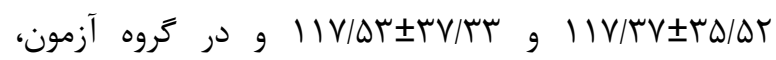

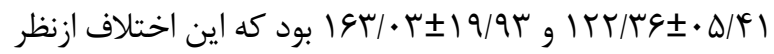

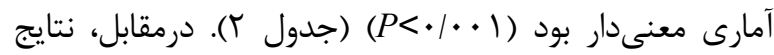

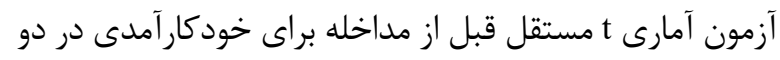

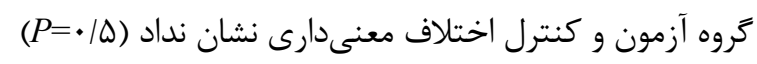

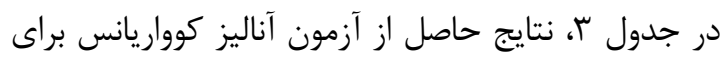

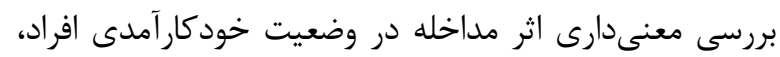

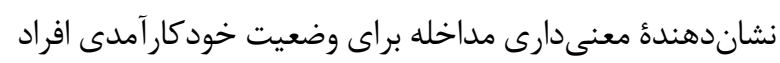
مطالعهده است. نتايج اين آزمون نشان داد كه در دو كروه دراثر دراثر

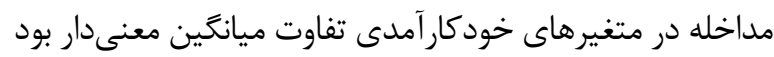

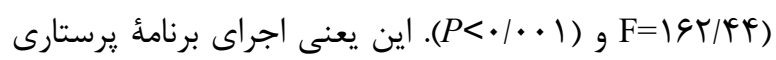
تلفنى (تلننرسينگ) توانست سطح خودكارآمدى بيماران مبتلا برانا

$$
\text { به ديابت نوع r را افزايش دهد. }
$$

استفاده شد. همجنين، براى مقايسُٔ واريانس ويزَّىهاى دو گروه، آزمون لون به كار رفت. درصورتى كه اين آزمون معنى دارى اختلاف

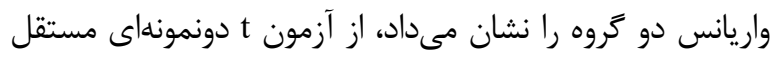

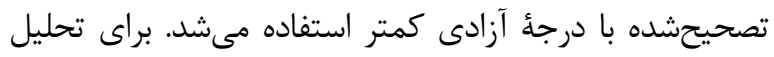

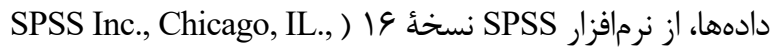

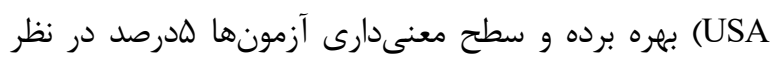
كرفته شد. شايان ذكر است علاوهبر كسب مجوز، رضايتنامة آنأ

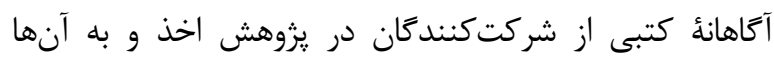
اطمينان خاطر داده شد كه تمام اطلاعات محرمانه است و در هر مرحلهاى از طرح كه بخواهند، مىتوانند از مطالعه خارج شوند.

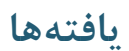

بهطور كلى، در اين مطالعه 9 × 1 نفر از زنان مبتلا به ديابت

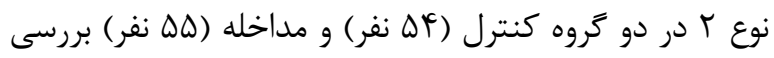

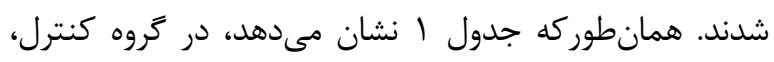

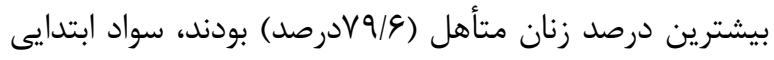

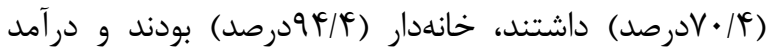

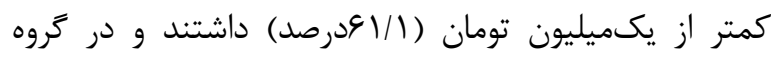

جدول ا. ارزش ويزه، درصد واريانس عاملها و درصد تراكمى واريانس تبيينشده در تحليل عاملى به روش مؤلفههاى اصلى

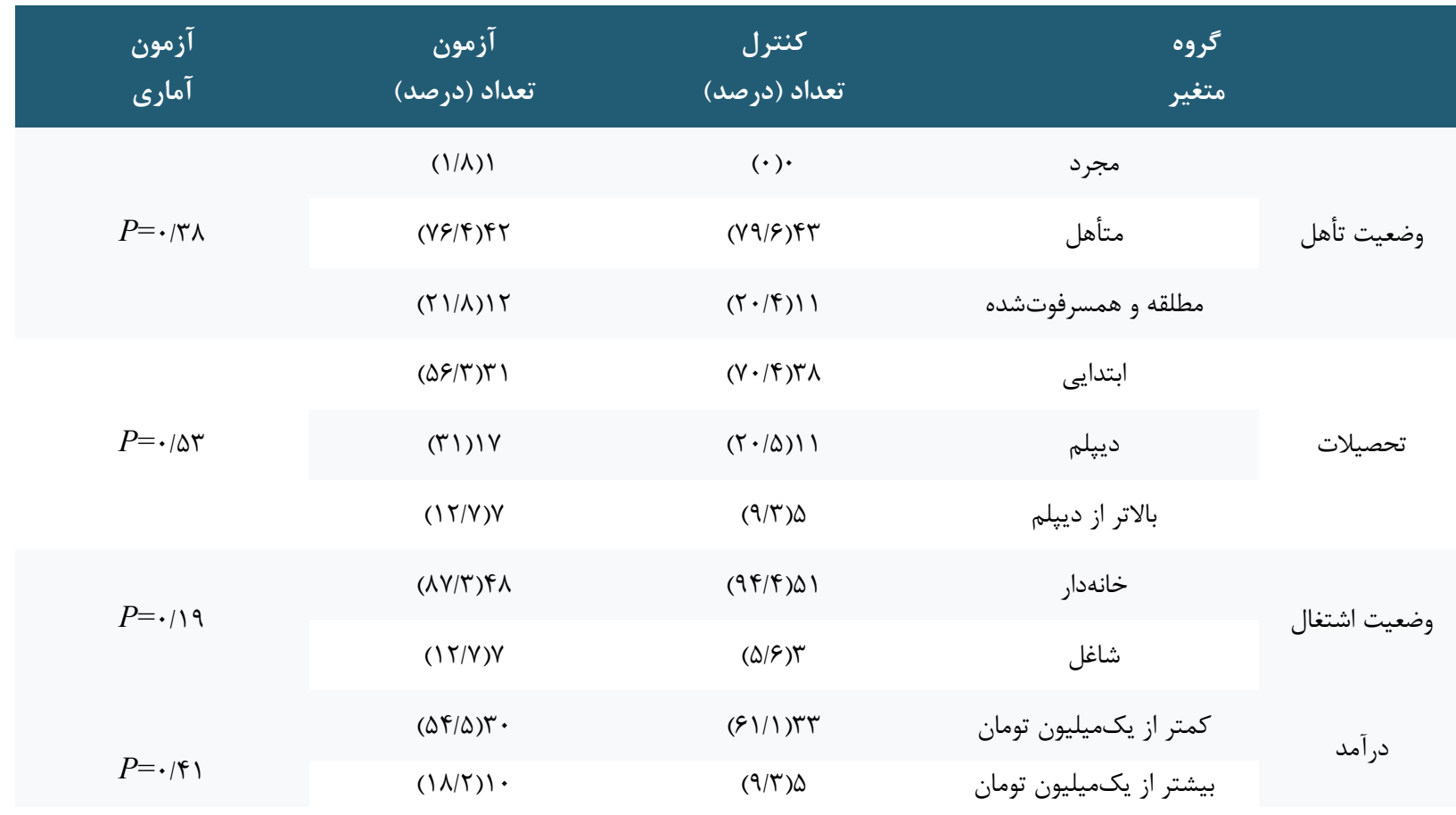


جدول r. توزيع فراوانى مطلق و نسبى وضعيت خودكار آمدى زنان مبتلا به ديابت نوع ك در دو تروه آزمون و كنترل قبل و بعد از مداخله

\begin{tabular}{|c|c|c|c|c|c|}
\hline 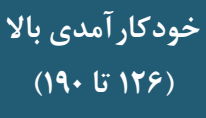 & 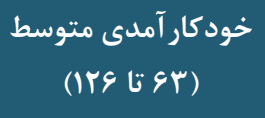 & 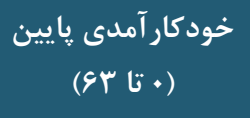 & & كَروهات & \\
\hline$(\Delta \cdot) T V$ & $(r \cdot / v) r T$ & $(9 / \Gamma) d$ & تعداد(درصد) & پِيش از مداخله & \multirow{2}{*}{ كنترل } \\
\hline$(\Delta \cdot) T V$ & (KT/G)KT & $(V / F) f^{q}$ & تعداد(درصد) & يّ از مداخله & \\
\hline$(\Delta r / V) r q$ & $(r N / r) \Gamma !$ & $(9 / 1) d$ & تعداد(درصد) & پِيش از مداخله & \multirow{2}{*}{ آزمون } \\
\hline$(G T / Y) Q 1$ & $(V / T)^{r}$ & $(\cdot) \cdot$ & تعداد(درصد) & يس از مداخله & \\
\hline
\end{tabular}

جدول ؟. ميانكَين و انحرافمعيار نمرات خودكار آمدى در بيماران مبتلا به ديابت نوع ب در كروه آزمون و كنترل قبل و بعد از مداخله

\begin{tabular}{|c|c|c|c|c|}
\hline آزمون t مستقل & ميانكَين土 انحرافِمعيار & تعداد & & شاخصها \\
\hline$P=\cdot / \Delta$. & $\| V / r \Delta \pm r V / \Delta r$ & $\Delta F$ & كنترل & \multirow{2}{*}{ پيش از مداخله } \\
\hline $\mathrm{t}=.1 .9$ & $|r r| \cdot \Delta \pm r G / F \mid$ & $\Delta \Delta$ & آزمون & \\
\hline $\begin{array}{c}P<\cdot / ., 1 \\
\mathrm{t}=\mathrm{V} / 9 \Delta\end{array}$ & $\| V / \Delta r \pm r V / r r$ & $\Delta F$ & كنترل & پِ از مداخله \\
\hline
\end{tabular}

بين يرستار و بيمار است [بّ]]. باتوجهبه عواملى نظير افزايش

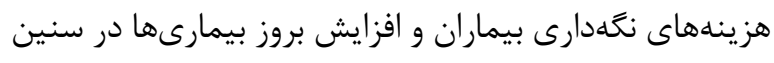

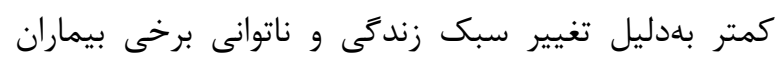

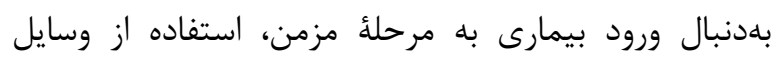

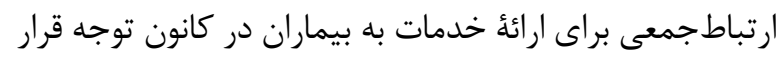

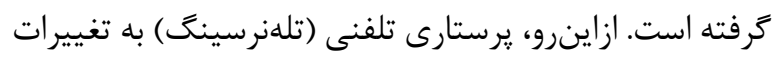

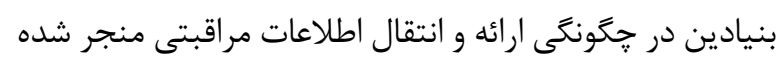

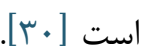
بروز هركونه بيمارى و مشكلات جسمى علاوهبر ايجاد

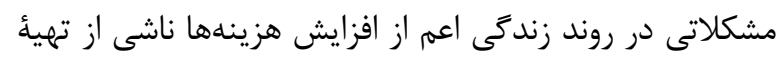

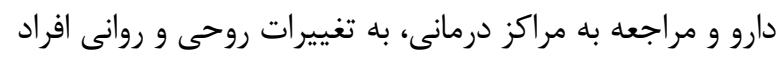

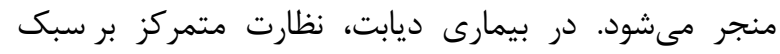

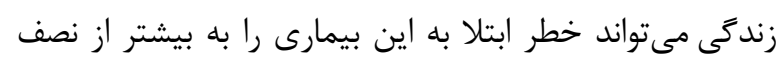

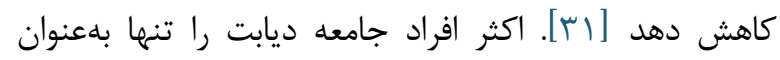

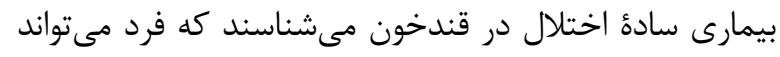

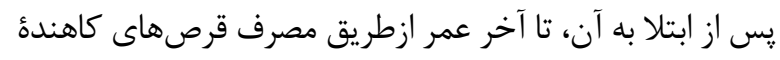

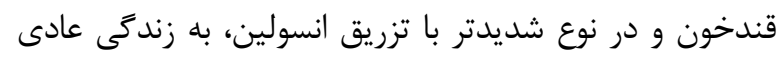

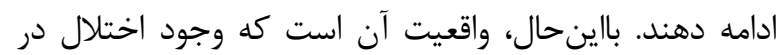

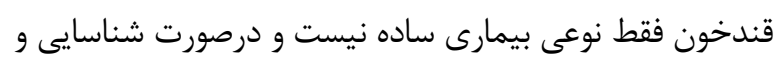

اين مطالعه با هدف بررسى تأثير آموزش و پِيخيرى تلفنى

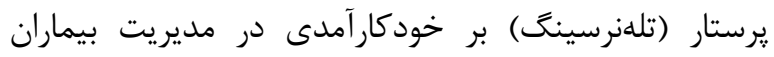

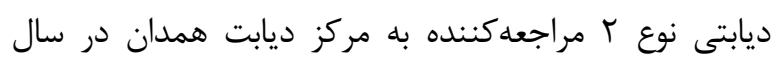

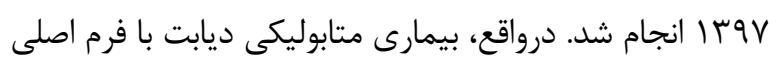

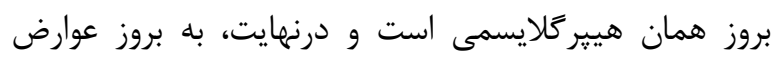

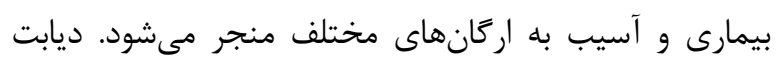

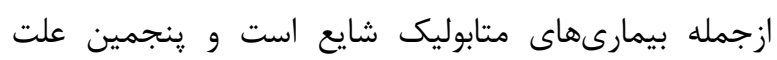

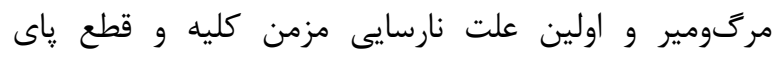

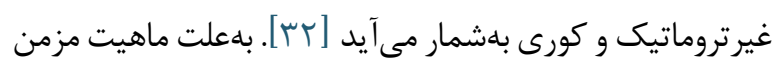

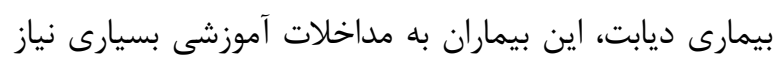

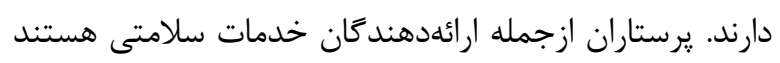

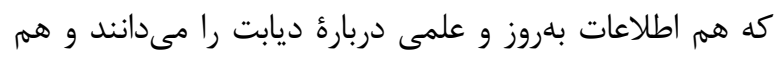
رسالت حرفئ آنان مراقبت است.

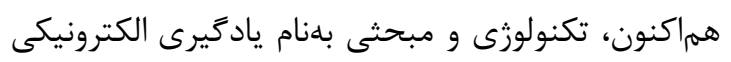

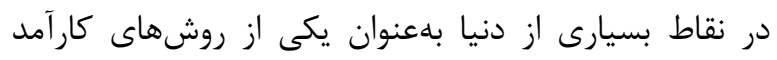

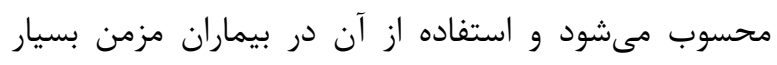

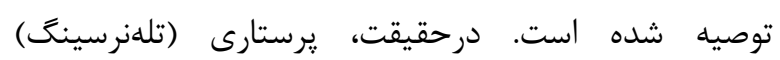

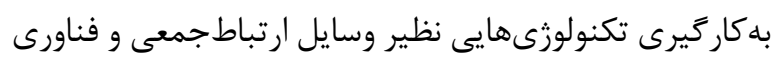

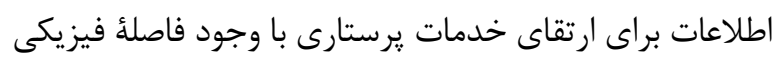


خودكارآمدى در مديريت ديابت بهعنوان عاملى پيشكويى كننده

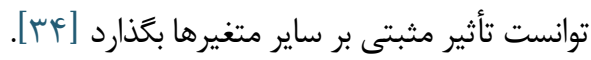

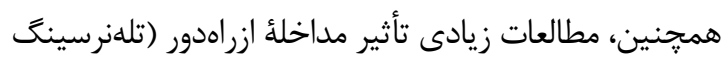

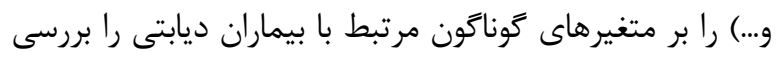

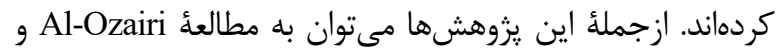
همكاران (Y.19) اشاره كرد. در اين تحقيق، مداخله مستقل بلهورت Tele Communication انجام شد و نكته مهمش اين اين بود كه مداخله بلصورت صحبتهاى بيشتر حمايتى انجام مى گرفت و در ميان اكثر مطالعات متمايز بود. بيشترِ مطالعات به دهاته

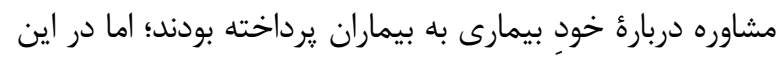

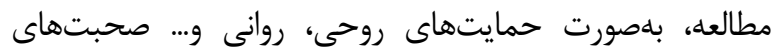

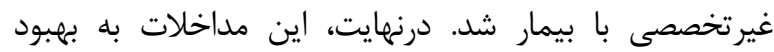
خودكارآمدى در مديريت ديابت انجاميد [هـار].

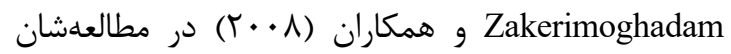
تأثير קֶيخيرى تلفنى يرستار (تلفنرسينگ) بر ميزان تبعيت از

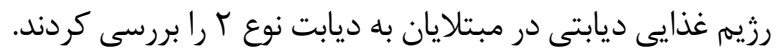

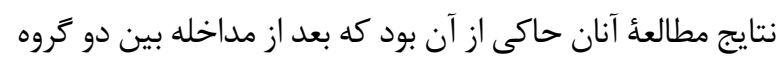

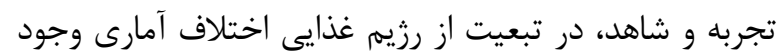
دارد و آزمون t مستقل نيز بعد از مداخله، اختلاف آمارى معنادارى بين دو كروه ازلحاظ ميزان هموكلوبين كليكوزيله

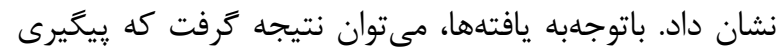
تلفنى يرستار به بهبود تبعيت از رزيم غذايى ديابتى و كاهش

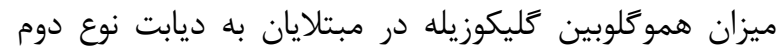

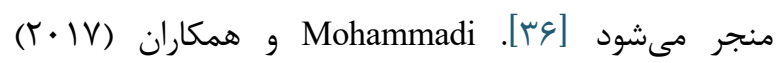

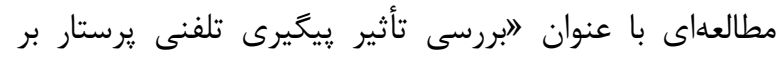

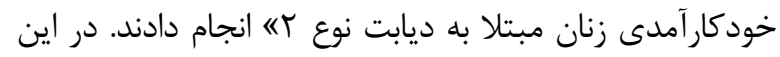
تحقيق، ميانكين نمره خودكارآمدى در كروه كنترل قبل و بعد از

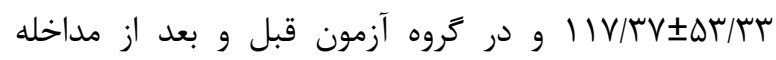
بلهترتيب | | آ/ع

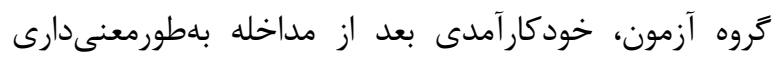

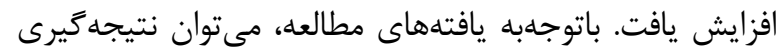

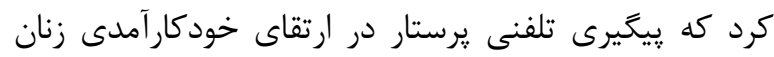

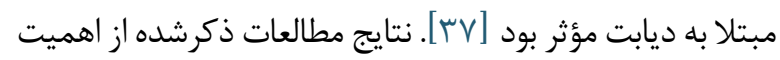
آموزش ازطريق شيوههاى نوين مانند آموزش ازراهدور حكايت

مى كرد و همكى در راستاى يزوهش حاضر بود.

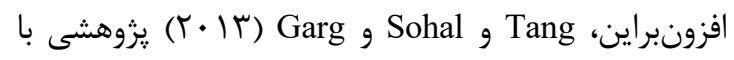
هدف تأثير آموزش همتايان بر خودكار آمدى و سطح هموكلوبين
مراقبت نشدن، مىتواند منشأ بسيارى از بيمارىهاى غيرواگير شود و برخى از اعضاى مههم و اساسى بدن، ازجمله قلب و كليه و جشمها را از بين ببرد [برَ].

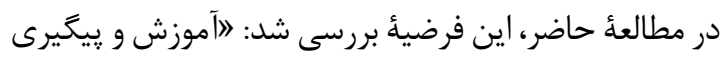
تلفنى يرستار (تلهنرسينگ) بر خود كار آمدى در مديريت بيماران

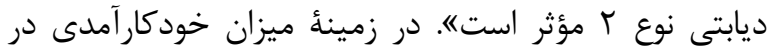

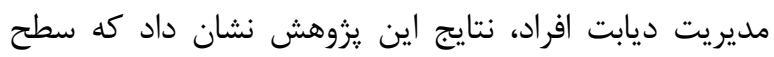
خودكارآمدى در مديريت ديابت افراد در موارد مختلف اعم از ارزيابى سطح قندخون، بررسى اندامهاى تحتانى نظير ياها، انجام

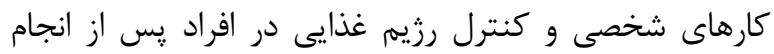

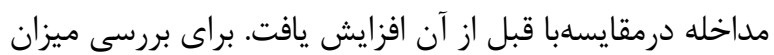

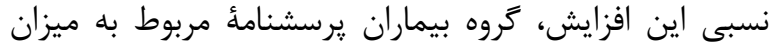

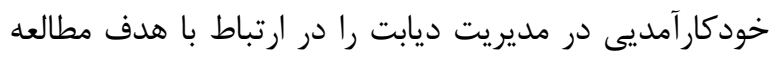

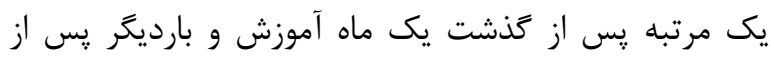

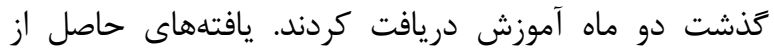

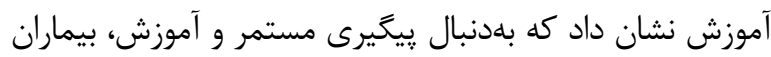

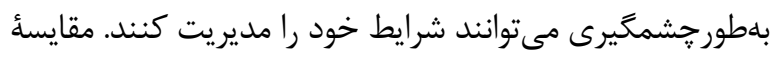

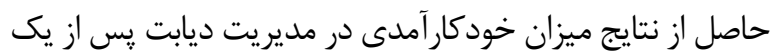

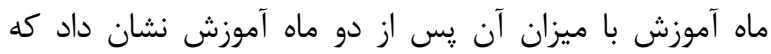

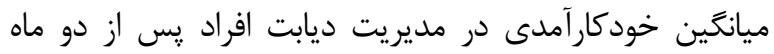

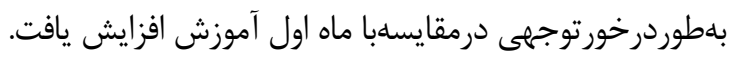

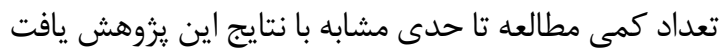

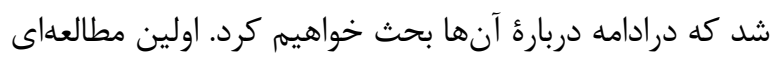

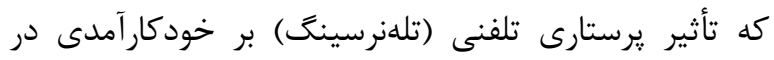

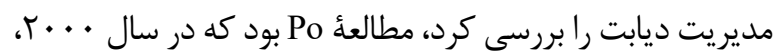

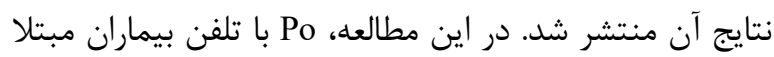

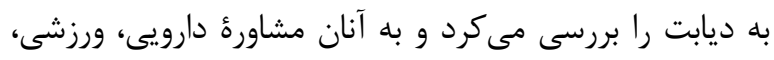
رفتارى و تغذيهاى مىداد. وى دريافت كه اين مداخلات

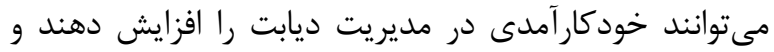

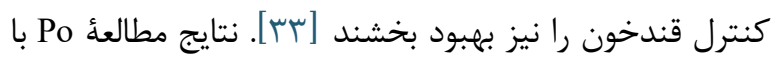

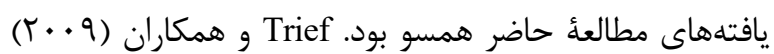
در مطالعهشان تأثير يزشكى ازراهدور بر شاخصهاى كإئلايسميك

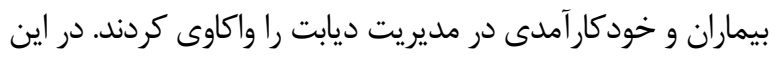

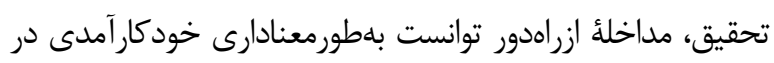
مديريت ديابت و شاخصهاى كلايسميك بيماران را بهببود بخشد. همجنين در اين مطالعه، بيماران داراى خودكارآمدى بيشتر در درائر

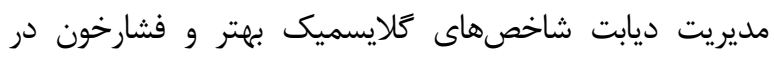
محدودة كنترل و عادات غذايى بهترى داشتند. درواقع، 
نتيجها كيرى

يافتههاى حاصل از اين مطالعه نشان داد كه آموزش و

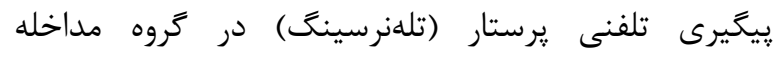
درمقايسهبا كروه كنترل موجب ارتقاى خودكارآمدى در

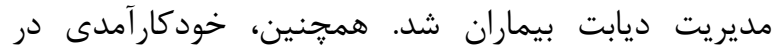
مديريت ديابت دو ماه بعد از مداخله در بيماران بلهورواضح بيشتر از يك ماه بعد از مداخله بود. مدئ مداه

$$
\text { سياسگَزارى }
$$

يزوهشگران از شوراى يزوهشى دانشكده و دانشعاه علوم

يزشكى همدان تشكر مى كنند. مقاله حاضر منتج از يايان نامهٔ كارشناسى ارشد يرستارى و كميتهٔ اخلاق دانشخاه علوم

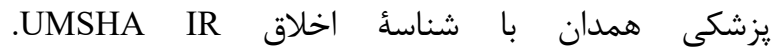

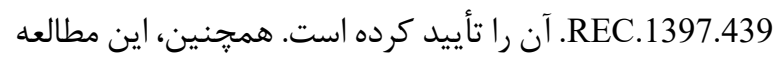

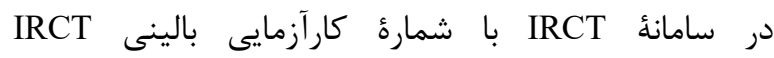
20120215009014N249 ثبت شده است. سماسه

$$
\text { تعارض در منافع }
$$

بين نويسندكان هيجز گونه تعارضى در منافع وجود ندارد
كليكوزيله بيماران ديابتى در ونكوور انجام دادند. يافتههاى اين مطالعه نشان داد كه بيماران گروه مداخله ازنظر متغيرهاى

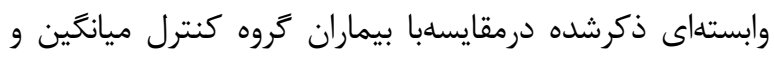
انحرافِمعيار بيشتر و كنترل همو كلوبين گليكوزيله بهترى داشتند

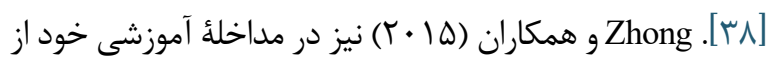
همتا و كاركنان مركز خدمات بهداشتى جامعه استفاده كرده بودند. آنان دريافتند كه مداخله همتا و كاركنان بهداشتى موجب افزايش خود كار آمدى عمومى، دانش، بهبود فشارخون سيستوليك

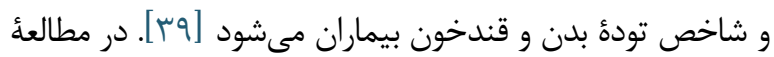

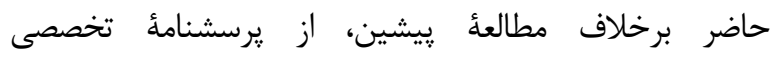
خودكار آمدى بيماران ديابتى استفاده شده بود. باتوجهبه نتايج اين مطالعه و مطالعات ييشين، ميىتوان جنين استنباط كرد كه علاوهبر تشخيص بلهموقع و درمان مناسب، بهبود روند درمانى و ييشخيرى از ديابت تا حد زيادى وابسته به خواست و اراده فرد در خودمديريتى و انجام رفتارهاى مرتبط با آن است. ازاينرو، اقداماتى كه به افزايش اعتماد و باور افراد در توانايى مراقبت از خود در مدت بيمارى منجر شود،

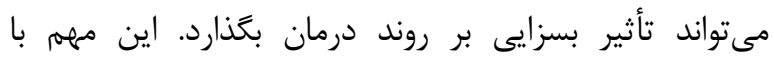
به كاركيرى روشهايى نظير يرستارى تلفنى (تلهنرسينگ) و و افراد كارآزموده و باتجربه امكانيذير است و مى مىتواند علاوهبر

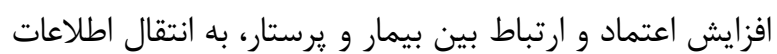
مفيد و مرتبط منجر شود. بيمار با تكيه بر اين اطلاعات و

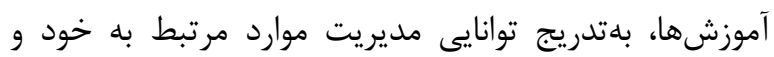
بيمارى را ييدا مى كند و درنهايت، اين روند سبب افزايش كيفيت زندكى مى مشود.

4. Fan W. Epidemiology in diabetes mellitus and cardiovascular disease. Cardiovasc Endocrinol. 2017;6(1):8-16. [DOI:10.1097/XCE.0000000000000116] [PMID] [PMCID]

5. Peykari N, Djalalinia S, Qorbani M, Sobhani S, Farzadfar F, Larijani B. Socioeconomic inequalities and diabetes: A systematic review from Iran. J Diabetes Metab Disord. 2015;14(1):8. [DOI:10.1186/s40200015-0135-4] [PMID] [PMCID]

6. Association AD. Diagnosis and classification of diabetes mellitus. Diabetes Care. 2014;37(Supplement 1):S81-S90. [DOI:10.2337/dc14-S081] [PMID] 
7. Moosazadeh M, Asemi Z, Lankarani KB, Tabrizi R, Maharlouei N, Naghibzadeh-Tahami A, et al. Family history of diabetes and the risk of gestational diabetes mellitus in Iran: A systematic review and meta-analysis. Diabetes Metab Syndr. 2017;11 Suppl 1:S99-S104. [DOI:10.1016/i.dsx.2016.12.016] [PMID]

8. Bate KL, Jerums G. 3: Preventing complications of diabetes. The Medical journal of Australia. 2003;179(9):498-503. 5377.2003.tb05655.x]

[DOI:10.5694/j.1326-

9. ASCHNER P, GAGLIARDINO JJ, ILKOVA HM, LAVALLE-GONZALEZ FJ, RAMACHANDRAN A, KADDAHA G, et al. Poor Glycemic Control in People with T1D and T2D-Results from the International Diabetes Management Practices Study (IDMPS). Am Diabetes Assoc; 2018. [DOI:10.2337/db18-1656-P]

10. Lin CC, Anderson RM, Chang CS, Hagerty BM, Loveland-Cherry CJ. Development and testing of the Diabetes Self-management Instrument: a confirmatory analysis. Res Nurs Health. 2008;31(4):370-80. [DOI:10.1002/nur.20258] [PMID]

11. Hammad S, Darawad M, Hourani E, Demeh W. Predictors of glycated hemoglobin among Jordanian diabetic patients. Iran J Public Health 2015;44(11):1482.

12. Chai S, Yao B, Xu L, Wang D, Sun J, Yuan N, et al. The effect of diabetes self-management education on psychological status and blood glucose in newly diagnosed patients with diabetes type 2. Patient Educ Couns. 2018;101(8):1427-32. [DOI:10.1016/j.pec.2018.03.020] [PMID]

13. Abaza H, Marschollek M. SMS education for the promotion of diabetes self-management in low \& middle income countries: a pilot randomized controlled trial in Egypt. BMC Public Health. 2017;17(1):962. [DOI:10.1186/s12889-017-4973-5] [PMID] [PMCID]

14. Sandelius S. Monitoring calls in telephone advice nursing: parents' and telenurses' experiences: Inst för neurobiologi, vårdvetenskap och samhälle/Dept of Neurobiology, Care Sciences and Society; 2017.

15. Mohammadi N, Soleymani R, Omidi A, Roshanae G. The Effect of Telephone Nursing Follow-up on SelfEfficacy of Females With Type 2 Diabetes Mellitus. Scientific Journal of Hamadan Nursing \& Midwifery Faculty. 2017;25(2):61-8. [DOI:10.21859/nmj-25028]

16. Balenton N, Chiappelli F. Telenursing: Bioinformation Cornerstone in Healthcare for the 21st Century. Bioinformation. 2017;13(12):412-4 [DOI:10.6026/97320630013412] [PMID] [PMCID]

17. Ralston JD, Hirsch IB, Hoath J, Mullen M, Cheadle A, Goldberg HI. Web-based collaborative care for type 2 diabetes: a pilot randomized trial. Diabetes Care. 2009;32(2):234-9. [DOI:10.2337/dc08-1220] [PMID] [PMCID]

18. Rehling B, Power MR, Power DJ. German deaf people using text communication: Short message service, TTY, relay services, fax, and e-mail. Am Ann Deaf. 2007;152(3):291-301. [DOI:10.1353/aad.2007.0030] [PMID]
19. Wong FK, Mok MP, Chan T, Tsang MW. Nurse followup of patients with diabetes: randomized controlled trial. J Adv Nurs. 2005;50(4):391-402. [DOI:10.1111/j.13652648.2005.03404.x] [PMID]

20. Smith-Strøm H, Igland J, Østbye T, Tell GS, Hausken MF, Graue M, et al. The Effect of Telemedicine Followup Care on Diabetes-Related Foot Ulcers: A Cluster Randomized Controlled Noninferiority Trial. Diabetes care. 2017:dc171025. [DOI:10.2337/dc17-1025] [PMID]

21. Johnson B, Quinlan MM, Marsh JS. Telenursing and Nurse-Patient Communication Within Fertility, Inc. J Holist Nurs. 2018;36(1):38-53. [DOI: $10.1177 / 0898010116685468]$ [PMID]

22. Hou C, Carter B, Hewitt J, Francisa T, Mayor S. Do mobile phone applications improve glycemic control (HbAlc) in the self-management of diabetes? A systematic review, meta-analysis, and GRADE of 14 randomized trials. Diabetes Care. 2016;39(11):2089-95. [DOI:10.2337/dc16-0346] [PMID]

23. Imani A, Dabirian A. Telenursing Benefits in patients with Diabetes: A Review Article. Adv Nurs Midwifery [Internet]. 2014Sep.17 [cited 2020Nov.25];23(83):65-4.

24. Lippman SM, Klein EA, Goodman PJ, Lucia MS, Thompson IM, Ford LG, et al. Effect of selenium and vitamin $\mathrm{E}$ on risk of prostate cancer and other cancers: the Selenium and Vitamin E Cancer Prevention Trial (SELECT). JAMA. 2009;301(1):39-51. [DOI:10.1001/jama.2008.864] [PMID] [PMCID]

25. Liddy C, Dusseault JJ, Dahrouge S, Hogg W, Lemelin J, Humbert J. Telehomecare for patients with multiple chronic illnesses: Pilot study. Can Fam Physician. 2008;54(1):58-65.

26. Baljani E, Salimi S, Rahimi J, Amanpour E, Parkhashjou M, Sharifnejad A, et al. The effect of education on promoting self efficacy in patients with cardiovascular disease. J Kermanshah Univ Med Sci. 2012;16(3):227-35

27. Haghayegh A, Ghasemi N, Neshatdoost H, Kajbaf M, Khanbani M. Psychometric properties of Diabetes Management Self-Efficacy Scale (DMSES). Iran J Endocrinol Metab. 2010;12(2):111-5, 95.

28. Van Der Ven NC, Weinger K, Yi J, Pouwer F, Ader H, Van Der Ploeg HM, et al. The confidence in diabetes self-care scale: psychometric properties of a new measure of diabetes-specific self-efficacy in Dutch and US patients with type 1 diabetes. Diabetes Care. 2003;26(3):713-8. [DOI:10.2337/diacare.26.3.713] [PMID] [PMCID]

29. Sabet SR, Hadian SZ. Diabetes diagnostic indexes and self efficacy of diabetic patients referred to Nader Kazemi center, Shiraz 2006. IJNR. 2009;4(14):15-21.

30. Glinkowski W, Pawlowska K, Kozlowska L. Telehealth and telenursing perception and knowledge among university students of nursing in poland. Telemedicine journal and e-health: the official journal of the American Telemedicine Association. 2013;19(7):523-9. [DOI:10.1089/tmj.2012.0217] [PMID] [PMCID] 
31. Orozco LJ, Buchleitner AM, Gimenez-Perez G, Roque IFM, Richter B, Mauricio D. Exercise or exercise and diet for preventing type 2 diabetes mellitus. The Cochrane database of systematic reviews. 2008(3):CD003054. [DOI:10.1002/14651858.CD003054.pub3]

32. Ripsin CM, Kang H, Urban RJ. Management of blood glucose in type 2 diabetes mellitus. Am Fam Physician. 2009;79(1):29-36.

33. Po YM. Telemedicine to improve patients' self-efficacy in managing diabetes. $\mathrm{J}$ Telemed Telecare. 2000;6(5):263-7. [DOI:10.1258/1357633001935888] [PMID]

34. Trief PM, Teresi JA, Eimicke JP, Shea S, Weinstock RS Improvement in diabetes self-efficacy and glycaemic control using telemedicine in a sample of older, ethnically diverse individuals who have diabetes: the IDEATel project. Age and Ageing. 2009;38(2):219-25. [DOI: 10.1093/ageing/afn299] [PMID]

35. Al-Ozairi E, Ridge K, Taghadom E, de Zoysa N, Tucker C, Stewart K, et al. Diabetes and TelecommunicationS (DATES) study to support self-management for people with type 2 diabetes: a randomized controlled trial. BMC Public Health. 2018;18(1):1249. [DOI:10.1186/s12889-018-6136-8] [PMID] [PMCID]

36. Zakerimoghadam $\mathrm{M}$, Bassampour $\mathrm{S}$, Rjab A, Faghihzadeh S, Nesari M. Effect of Nurse-led Telephone Follow ups (Tele-Nursing) on Diet Adherence among Type 2 Diabetic Patients. Hayat. 2008;14(2):63-71.

37. Mohammadi N, Soleymani R, Omidi A, G R. The Effect of Telephone Nursing Follow-up on Self-Efficacy of Females with Type 2 Diabetes Mellitus. Avicenna J Nurs Midwifery Care. 2017;25(02):61-8. [DOI:10.21859/nmj-25028]

38. Tang T, Sohal P, Garg A. Evaluating a diabetes selfmanagement support peer leader training programme for the English-and Punjabi-speaking South-Asian community in Vancouver. Diabetic Medicine. 2013;30(6):746-52. [DOI:10.1111/dme.12179] [PMID]

39. Zhong X, Wang Z, Fisher EB, Tanasugarn C. Peer support for diabetes management in primary care and community settings in Anhui Province, China. The Annals of Family Medicine. 2015;13(Suppl 1):S50-S8. [DOI:10.1370/afm.1799] [PMID] [PMCID] 